\title{
A dignidade da pessoa humana e o mínimo existencial*
}

Cármen Lúcia Antunes Rocha**

De acordo com o tema proposto, minhas observações serão expostas a partir de uma visão de direito constitucional contemporâneo, além de pontuar alguns itens sobre o princípio da dignidade da pessoa humana e o mínimo existencial.

Sabemos que o mínimo existencial convive com o princípio da chamada reserva do possível, que não pode anular o que foi conquistado pela pessoa, mas também não pode impedir que o Estado continue agindo. Portanto, começo minhas colocações a partir daquilo que realmente acredito seja essencial ao constitucionalismo contemporâneo, para chegar a algumas posições aceitas sobre o tema e alguns problemas com os quais somos obrigados a conviver e enfrentar para que sejam resolvidos. Assim, de forma geral, existem alguns dados essenciais do constitucionalismo contemporâneo e o direito é uma conquista permanente. Vivemos, atualmente, momentos constantes e determinantes. Penso que essas conquistas,

\footnotetext{
* Palestra proferida na Escola de Direito do Rio de Janeiro da Fundação Getulio Vargas (FGV Direito Rio), em 18 set. 2009, no âmbito do projeto "Diálogos com o Supremo", realizado pelo Programa de Mestrado em Poder Judiciário. O texto decorre de gravação da palestra e não contou com revisão da palestrante.

** Ministra do Supremo Tribunal Federal desde 2006. Professora titular e coordenadora do núcleo de direito constitucional da Faculdade Mineira de Direito da Pontifícia Universidade Católica de Minas Gerais (PUC Minas). Membro da comissão de estudos constitucionais do Conselho Federal da OAB (1994), da comissão de reforma constitucional da seccional mineira da OAB (1993), membro efetivo do Instituto dos Advogados Brasileiros (IAB), membro fundadora do Instituto de Defesa das Instituições Democráticas (Idid) (1997), membro do conselho editorial da Revista Interesse Público e do conselho editorial do Boletim NDJ. Exerceu os cargos de advogada e procuradora do estado de Minas Gerais.
} 
em grande parte, foram acolhidas pelo constitucionalismo positivo brasileiro a partir de 1987/88. Ou seja, o constituinte observou tudo isso e nós estamos tentando efetivar.

O primeiro desses traçados é exatamente o princípio da dignidade humana como norma jurídica. Claro que o princípio da dignidade da pessoa humana não está apenas no direito. Esse princípio não é reserva do direito e não é respeitado apenas porque está no inciso III do artigo $1^{\mathrm{o}}$ da Constituição Federal, mas deriva da circunstância de termos uma norma constitucional. Sempre ressalto que a Constituição é lei. Ela não é aviso, não é cartilha, não é proposta. A Constituição é uma lei com qualificação especial, da qual decorrem todas as outras. Aliás, o Brasil já teve constituição que nem nome de constituição tinha, mas era observada como se assim fosse na hierarquia das normas de mais alto escalão, como foi a Emenda $\mathrm{n}^{\mathrm{o}}$ 1. O Brasil também teve documento com nome de constituição, mas as leis não eram aplicadas, como o caso da Carta de 1937. Neste momento atual de democracia, a Constituição brasileira é a lei maior deste país. Ela é a lei que fundamenta a convivência democrática em sociedade.

Para o direito constitucional brasileiro contemporâneo, esse princípio é magno. O Código Penal e o Código Civil são analisados a partir da Constituição e a Constituição a partir do inciso III, do art. $1^{\circ}$. Nos períodos autoritários e ditatoriais, a população brasileira não tinha a menor ideia do que seria a Constituição. Hoje, ela é a lei que fundamenta todas as outras. Partimos dela e chegamos a ela. E é através dela que se chega ao princípio da dignidade. E esse princípio precisa ser muito bem definido. Não é algo que seja exclusivo de quem ingressa em uma faculdade de direito. Penso que nós da área jurídica somos operários do direito e não operadores do direito. E isso é uma responsabilidade maior, pois, temos o dever de acatá-lo e fazer com que ele seja acatado. Como? Interpretando e aplicando esse princípio a um caso concreto.

O segundo ponto a ser abordado é o direito constitucional contemporâneo, que passou a considerar o ser humano como um ser de carne e osso; talvez eu esteja dizendo o óbvio, aliás, é mesmo o óbvio, mas chamo atenção a isso porque, no Brasil e até mesmo nos dias de hoje, o povo ainda é um ícone. Quem é o povo? Fala-se "o povo" para não satisfazer ninguém. Na verdade, as expressões "pessoa humana" e "ser humano" já foram utilizadas dessa forma, como um ícone, como algo que era para ser preservado, mas não concretizado. Felizmente, o direito fez com que isso acabasse e, hoje, quando falamos em dignidade da pessoa humana, da forma como está no inciso III do art. $1^{\circ}$ da Constituição, falamos como Carlos Drummond de Andrade em seu texto "Nosso tempo" escrito no final da Segunda Guerra Mundial: “Os homens pedem carne. Fogo. Sapatos”. A mesma história foi muito bem expressada por Ulisses Guimarães na tarde de 5 de outubro de 1988, quando disse que o grande problema da sociedade brasileira era o cidadão sem 
casa, sem comida, sem sapatos, sem remédio, enfim, o grande problema era o homem sem cidadania. $\mathrm{O}$ resultado de todo esse processo deve ser o respeito e a dignidade para os quase 200 milhões de brasileiros atualmente. Dignidade que é igual para todos no que se refere à humanidade, que faz com que sejamos diferentes. $\mathrm{O}$ respeito à dignidade está contido na humanidade. Minha abordagem torna o ser humano num ser concreto. Não em algo virtual ou genérico. Isso se torna importante e nos faz refletir que não julgamos papel, mas sim pessoas de carne e osso, vidas. Isso vale para o motorista que não respeita o sinal de trânsito. Ele deve saber que aquele que atravessa a rua é um ser humano. Isso vale para nós juízes, que sabemos que mesmo nos tribunais superiores não estamos julgando papel, mas sim a vida de uma pessoa de carne e osso.

O terceiro ponto a considerar é que 21 anos depois da promulgação da Constituição Federal, o que era novidade em 1988, ou seja, o texto do art. 1ํㅡㄹ inciso III, que diz: "A República Federativa do Brasil, formada pela união indissolúvel dos Estados e Municípios e do Distrito Federal, constitui-se em Estado democrático de direito e tem como fundamentos: [...] III - a dignidade da pessoa humana...", passou a não ser mais. Hoje, o Supremo julga questões sobre células-tronco, se o feto e/ou essa célula são pessoas ou não. Para o direito, célula-tronco e feto não são considerados pessoas. No direito, pessoa é um conceito bem definido: é alguém com direitos, deveres e responsabilidades. Portanto, o genoma não é considerado pessoa. E é nesse ponto que o direito mudou. Ele não se preocupa com a pessoa humana conforme estabelecido na Constituição. O direito se preocupa com o ser humano. Para ele, o feto não é pessoa. Aquela parte da mulher que é utilizada como célula-tronco pode se constituir em ser, portanto, o que importa agora ao direito, e que não era ainda motivo de atenção em 1988, hoje é assunto pacificado: importa-nos a espécie humana. Tudo que fizer mal à espécie humana pode estar a contrariar norma constitucional. Não preciso identificar.

Quando eu era estudante universitária, a cada área do direito havia um titular. Com a Constituição, as condições saudáveis do meio ambiente, por exemplo, passaram a ser responsabilidade do Estado e, principalmente, da sociedade. Refiro-me a um titular do direito que não existe mais e que não sei se vai existir. Com a mudança, o direito não se reporta mais a sicrano, a beltrano. Ele se refere à humanidade no sentido amplo. Como juíza constitucional, sou obrigada a prestar muita atenção quando deparo com alguma causa, por exemplo, sobre o meio ambiente. Então, eu posso pensar: mas não tem ninguém para reclamar? E é por isso que existe um "advogado" da sociedade, que é o Ministério Público. A sociedade não consiste apenas em mim. Ela é um conjunto de pessoas. Enfim, mudamos a tônica do direito.

Destaco ainda o quarto ponto importante relacionado ao assunto: como bem chama a atenção Paulo Bonavides, na esteira do constitucionalismo contemporâ- 
neo, a Constituição Federal brasileira é aberta. Cornelius Castoriadis (1922-1997), filósofo grego radicado na França, afirma: “Tanto mais democrática é a sociedade, quanto mais em aberto nela estiver a ideia de justiça", porque a ideia de justiça é dinâmica, ou seja, o que é justo hoje, provavelmente não era no passado, nem será no futuro. Por isso mesmo é que o art. $1^{\circ}$ da Constituição Federal fala em Estado democrático de direito e não em Estado de direito. Em outras palavras, o direito deve estar em aberto para assim permitir a ideia de justiça. Não podemos permitir que uma geração amarre as gerações futuras. Não permitimos essas amarras por parte dos nossos pais.

Essa ideia de Constituição em aberto, no entanto, não significa que cada um possa fazer o que bem entender. Tenho observado até mesmo através da mídia grandes comoções populares e vejo pessoas clamando por pena de morte. O Brasil não pode ter pena de morte. Os federalistas John Jay e James Madison, autores do livro O Federalista, dizem que o juiz mostra mais a sua coragem em momentos de fortes comoções populares, porque o direito é a barreira, a razão que se mostra para que a emoção não tome conta e a mais ampla injustiça seja cometida. O ser humano em momento de raiva pode cometer grandes injustiças. Nos termos da razão, o que está posto é o que deve ser cumprido.

Essa ideia de Constituição Federal aberta é nova pelo menos em parte. Ela permite que a sociedade ande. O direito é uma ciência antiga e vem a reboque da sociedade. Essa ideia precisa ser amadurecida e não ficar para trás. O constitucionalismo contemporâneo precisa ser pensado. Devemos abandonar o instrumental velho e dar lugar a novas realidades. A sociedade tem reclamado esse emperramento no direito. A morosidade da justiça é um problema do Judiciário ou não? Se todos os processos forem julgados com rapidez, o Judiciário ficará ocioso? Nem sempre o discurso detém a verdade total.

Estamos fazendo uso de um arsenal antigo. Fico muito feliz porque o povo brasileiro tem falado de Constituição, o que é uma grande novidade. Quando comecei a lecionar direito constitucional, as pessoas não sabiam nem do que se tratava. Lembro-me de outro poema de Carlos Drummond de Andrade intitulado "A Afonso Arinos, setentão", em que ele diz: "Afonso, meu combatente do direito e da justiça, nosso exato professor do direito mais precário (o tal constitucional)...". Hoje, as pessoas sabem o que significa o direito constitucional.

No Brasil, algumas coisas pegam. A ideia de constituição pegou a partir de 1988. Há pouco tempo participei de um debate na Escola Judiciária Eleitoral, do Tribunal Superior Eleitoral, sobre voto obrigatório e voto facultativo. Um dos participantes manifestou sua perplexidade em saber que a Justiça Eleitoral é uma "jabuticaba" brasileira, ou seja, é uma criação brasileira. Não existe em outro lugar. E é uma estrutura, que não existe em outro lugar, que deu certo, assim como a jabuticaba. E na ocasião, disse ao participante que existem outras estruturas legi- 
timamente brasileiras, como é o caso, por exemplo, do mandado de segurança. Só há no Brasil e foi algo que deu certo.

Para se falar em dignidade da pessoa e mínimo existencial, penso que é preciso saber que a Constituição Federal se democratizou e se tornou um tema comum para todos. Mas é importante que as pessoas saibam que o direito não faz milagre. Ele está aí para que as leis sejam aplicadas da melhor forma possível. Nós, do Judiciário, não somos milagreiros. Costumo dizer isso quando alguns advogados chegam pedindo o que pode ou o que não pode, o que tem e o que não tem na Constituição. Digo: olhe, eu adoraria, você é bem-vindo, mas deveria dirigir seu pedido a Deus diretamente para realizar esse milagre. Na verdade, não faz parte a Constituição pela sua promulgação. Sua vigência não significa transformação social, até porque já tivemos constituição de prateleira. Esta não é, mas é preciso que se aplique e que toda a sociedade aplique.

Hoje, temos os efeitos privados dos direitos fundamentais, ou seja, não adianta o cidadão cobrar do Estado o respeito aos seus direitos fundamentais sem que ele respeite o direito fundamental do seu vizinho, por exemplo. Não adianta exigir respeito sem a contrapartida do respeito. É preciso que os direitos fundamentais sejam entendidos não como obrigação apenas do Estado, mas como obrigação de cada cidadão. E é a partir daí que podemos conceber o direito da dignidade da pessoa humana, porque o direito não faz milagre, mas existe para que as pessoas tenham a oportunidade de conviver de forma harmônica. E é aí que a Constituição Federal é uma constituição da sociedade para a sociedade. E isso ainda é uma grande novidade no Brasil.

A Constituição dos EUA não criou os EUA, mas a Convenção de Filadélfia criou os EUA, que não existiam - havia 13 colônias, que se transformaram em 13 estados soberanos e cada um com a sua constituição. Na Convenção de Filadélfia foi criado o Estado Nacional, que hoje conhecemos como Estados Unidos da América do Norte. No Brasil, não foi o povo que criou a Constituição Federal, nem a Constituição criou o povo brasileiro. O povo é que esteve ao lado das constituições. O processo acontece mais ou menos assim: existe uma sociedade, a sociedade política amadurece e resolve crescer num determinado estado. Como é pessoa de direito, essa sociedade cria a lei fundamental, que dá, para se usar uma expressão atual, o DNA do estado. No Brasil foi convocada a primeira constituinte em 13 de junho de 1822. O grito às margens plácidas do Ipiranga teria sido em 7 de setembro do mesmo ano. Não havia estado. Quem era a sociedade? O grito do Ipiranga não foi transmitido via satélite para todo o Brasil, tanto que alguns estados do nordeste comemoram esse acontecimento em outras datas. Percebe-se com isso que a consolidação da sociedade como uma sociedade brasileira não é da mesma época. E as constituições são criadas sem uma consulta prévia ao povo. 
Portanto, isso precisa ser mudado. A Constituição Federal já foi alterada 64 vezes sem que o povo tenha sido consultado previamente. E digo mais: em decorrência das várias mudanças, existem até professores de direito que não sabem quantas emendas constitucionais foram criadas. Embora o povo não seja consultado previamente, as mudanças pelo menos têm ocorrido e isso denota um dado de transformação ao longo desses quase 22 anos da promulgação da Constituição Federal.

O Brasil ainda vive uma situação de desigualdade social demasiadamente forte. E isso afeta profundamente a dignidade da pessoa humana. As diferenças sociais são tão estampadas que podem ser vistas, por exemplo, no céu de São Paulo: muitos se deslocam de helicóptero, enquanto outros vão ao trabalho a pé, muitas vezes andando quilômetros. Há ainda, em se tratando do Nordeste do Brasil, os que vão trabalhar montados no lombo de um jumento ou crianças que, para estudar, são transportadas na carroceria de algum caminhão. E o pior, quando chegam à escola, essas crianças não têm lugar para sentar, tal a precariedade da instituição. Enquanto isso, outras crianças são alfabetizadas em ótimos colégios que ensinam ainda duas ou três línguas estrangeiras. Ou seja, o Brasil vive uma desigualdade social tão grande, que se torna difícil sua mensuração. A lei deve ser revista. Ela não pode ser aplicada num município pequeno da mesma forma que é numa cidade grande. A realidade e as necessidades são distintas e devem ser observadas.

Por isso é que, quando eu era chefiada pelo ministro Marcílio Marques Moreira na Comissão de Ética, várias vezes disse, e continuo dizendo ao ministro, que acho que a questão de números de servidores públicos precisa ser entendida. Num município pequeno que só tem o professor, o posto de saúde e que não tem nenhuma fábrica, nem estrada, às vezes ter $70 \%$ dos recursos destinados ao funcionalismo público é uma forma de sobrevivência, embora ela não possa ser permanente porque senão aquele modelo é estancado e pode levar realmente a nunca mudar isso, a manter esse status. Porém, quando vejo que a pessoa não tem acesso (poucos dias aconteceu com um conhecido meu, ele teve de viajar 450 quilômetros de carona para levar um filho que estava com apendicite supurada até o primeiro hospital por uma estrada de terra), a pessoa não tem nem emprego (e isso não é nada incomum), você vê muitas humanidades vivendo tempos diferentes no mesmo país. E o Brasil tem um problema que precisamos superar: aqui leva-se o consumo antes de levar a civilização. Há poucos dias, vi uma pessoa montada num jeguinho, indo com duas broacas, onde levava o que tinha plantado para vender na feira, e com um celular. Tinha celular, que é algo de hoje, mas não tinha acesso a um carro ou a um ônibus para ter a segurança de ir aos lugares. Isto acontece desde sempre. A Corte portuguesa chegou ao Brasil em 1808 e alguns anos depois foram criadas a Faculdade de Direito, a Faculdade de Olinda e a Faculdade de São Paulo. Houve a preocupação, na monarquia, em criar cursos superiores, mas não em criar insti- 
tuições de ensino fundamental que resolvessem os problemas, até os dias atuais, de analfabetismo, exclusão e evasão escolar. E é exatamente esse desvio antigo que precisa ser consertado rapidamente. A sociedade precisa saber que a civilização vem antes do consumo. Ela precisa tomar conhecimento da sua liberdade de consumir não por obrigação, mas por livre vontade. A sociedade deve aprender a fazer suas escolhas e viver uma democracia plena. Todos sabemos que a falta de acesso à informação condena o cidadão à ignorância e não o faz um ser inteiramente livre. Penso que esse seja o principal problema dos últimos tempos.

Esses desequilíbrios, mais do que desigualdades, fazem com que a atuação do Estado seja realmente mais difícil. Enquanto governos de países evoluídos (França e Alemanha, por exemplo) fazem políticas públicas voltadas aos seus cidadãos, o Brasil ainda vive situações precárias que deveriam ter sido erradicadas há muito. Enfim, tenta eliminar questões básicas, como o analfabetismo, que fragiliza e envergonha o ser humano.

A Constituição Federal brasileira tem sido vista atualmente como "carta das liberdades", e por isso ela centralizou a dignidade da pessoa humana como ponto de partida e ponto de chegada da interpretação do direito e da aplicação da ação desse direito em qualquer nível e em qualquer seara. Porém, penso que passados os primeiros quase 22 anos de consolidação das instituições, especialmente das instituições políticas, devemos passar para os compromissos sociais com a Constituição e pela Constituição. Até agora se cobrou do Estado o cumprimento da Constituição, porém, ela é apenas projeção jurídica de um programa político feita para uma sociedade de carne e osso.

Por que digo isso? Porque acho que também passou a ideia de que a Constituição haverá de ser uma carta da libertação. Uma carta que permita a transformação, mas a partir dela, e nos termos do que foi posto por ela, porque a libertação é dinâmica. A Constituição Federal deve propiciar condições de igualdade. Passados quase 22 anos da promulgação constitucional, o Brasil ainda vive, como dissemos anteriormente, uma completa desigualdade social, em que as minorias são massacradas a cada dia.

Certa vez, o professor José Gomes Canotilho me perguntou por que escrevo sobre igualdade de forma diferenciada. Respondi que também sofro preconceito pelo fato de ser mulher e por ser uma profissional atuante. Não podemos negar que muita coisa melhorou nos últimos anos, mas ainda falta bastante. Faltam dignidade, respeito e individualidade. Faltam os ingredientes estabelecidos pela Constituição Federal para a consolidação de uma sociedade plural e igual. Chegamos a um ponto de igualdade? Não, não chegamos. Ou seja, falta um processo dinâmico de superação de preconceitos e isso a Constituição Federal garante, mas quem pode fazer é a sociedade, não o Estado. O Estado pós-1988 pode fazer a mes- 
ma coisa que podia antes, proibindo concurso público ou qualquer discriminação, ou então estabelecer cotas, ou qualquer tipo de ação afirmativa para permitir que grupos que sofreram mais tenham a reposição para que, com a convivência, seja superado o preconceito. Há pelo menos medidas que podem ser adotadas. Agora, o preconceito é um conceito prévio, dificilmente muda.

No Brasil, a abordagem sobre direitos sociais é mais complicada. As desigualdades, os níveis diferenciados de possibilidades e oportunidades sociopolíticas, enfim, tudo isso se torna uma questão complicada porque o Estado vem se formando primeiramente para garantir a liberdade individual. Esse mesmo Estado moderno assevera que o ser humano sozinho é frágil e o obriga a conviver em sociedade para ficar mais forte. Ocorre que, para isso, o cidadão abre mão de uma parcela da sua liberdade e passa a não poder fazer de forma voluntária o que deseja. Trata-se do primeiro modelo de Estado e é o primeiro tempo de pós-Revolução Francesa, período revolucionário. Depois se diz: mas não adianta, se o outro também não tiver a igualdade de oportunidade, ele sempre será um adversário ou, quando nada, um inimigo. Então, partimos para o Estado social. Chegou-se à conclusão de que mesmo aqueles estados que já tinham chegado a um Estado social teriam uma diferença enorme no mundo com os estados muito pobres, porque o pobre seria "uma ameaça permanente", uma vez que eu teria um desequilíbrio e aí se chega a um Estado de previdência, uma busca de igualação contra a pobreza. A pergunta que faço é: no Brasil, o Estado que surge no primeiro tempo para garantir a minha liberdade individual já aconteceu? Posso andar na rua à noite, sem medo do outro? Porque até observo que, em alguns momentos, esse primeiro estágio do Estado ainda não foi alcançado, basta ver o tipo de sociedade que estou criando dentro da minha casa.

Que sociedade temos? Que sociedade queremos ter? Como podemos viver nela? Somente o direito constitucional pode possibilitar as respostas a essas indagações. E quando ressalto que temos um instrumental velho para questões novas, me lembro do meu grande amigo Calmon de Passos, que dizia:

O problema de hoje [ele era processualista constitucional] não é falta de esperança. Todo o mundo tem um dia melhor, um dia pior, um dia em que está muito bem, um dia em que acha que está navegando em ótimas águas. De repente vem uma onda maior e você se vê emparedado, mas dorme e acorda com a ingênua e necessária suposição de que volta a ter esperança e faz a sua ressurreição todo o dia, acreditando que a esperança se renova.

O problema do brasileiro não é falta de esperança. Se assim fosse, ele já teria sucumbido há muito tempo. O maior problema do século XXI é a falta de efetividade na aplicação das leis. E aí chego à questão expressa na Constituição, desde 
o preâmbulo, passando pelos arts. $1^{\circ}, 2^{\circ}, 3^{\circ}, 5^{\circ}, 6^{\circ}$ e $7^{\circ}$. Se todos forem cumpridos como estabelecido, o Brasil corre o sério risco de cair numa democracia permanente e como diz Tom Zé em "Rio arrepio (badi-badá)": “a felicidade vai desabar sobre os homens". Cumpridos esses preceitos, teríamos realmente um Brasil em que a dignidade da pessoa, da espécie humana, estaria devidamente garantida. Bobbio dizia que o problema não é conquistar novos direitos, que a partir do princípio da dignidade da pessoa humana você pode extrair muitos outros direitos, mas eles já estão, ainda que implicitamente, nos sistemas. O que você quer? Você quer que os direitos que foram conquistados se convertam na realidade da vida das pessoas, até porque a palavra solta da lei não vale muita coisa; vale quando se torna efetiva.

No art. $1^{\circ}$ da Constituição Federal, encontramos a dignidade da pessoa humana e a cidadania, além do valor do trabalho. Algo que anda muito em desuso atualmente.

A Constituição Federal garante o mínimo necessário (material, psicológico e social) para que o cidadão tenha condições de sobrevivência. O Estado deve garantir o direito à liberdade, à igualdade, ao trabalho, à moradia, ao lazer, à educação, à previdência, ao amparo, à assistência aos necessitados.

A Constituição Federal exige que pelo menos 25\% dos recursos arrecadados pelos estados sejam destinados para a educação e 12\% para a saúde. Até 2013 ou 2014, os estados têm, devido a contratos assinados em 1998 com o governo federal, dívidas da ordem de $13,75 \%$ para com a União. Contabilizando-se $25 \%$ mais $12 \%$, o estado passa a ter uma dívida de 37\%, somando-se mais 13,75\%, o montante chega a mais de 50\%. Tendo o Estado uma folha de $40 \%$, o que é razoável, sobram 10\% para tudo o mais. Em Minas Gerais, desde a década de 1950 até 2002, não havia a arrecadação dos $25 \%$ para a educação ou ela era acatada e não havia verba para a saúde porque ainda faltavam $13,75 \%$, além de uma folha de pagamento que ultrapassava os 50\%. Isso tudo acarretava um déficit monstruoso.

Quanto às políticas assistencialistas, não tenho muita simpatia, mas o governo não pode, por exemplo, deixar um ser humano passar fome. Porque a fome machuca. Imagine uma criança que não sabe quando vai comer ou que não tem a menor ideia se algum dia vai conseguir estudar. Isso é muito triste! Que sociedade é essa que estamos formando? É isso que a Constituição Federal estabelece? Definitivamente não! Ela estabelece o mínimo existencial necessário. De acordo com a Constituição Federal, isso é obrigação do Estado e da sociedade.

$\mathrm{Na}$ verdade, não tenho dúvida nenhuma de que é preciso repensar os modelos de produção, porque não acredito na morte do socialismo. O socialismo é a poesia na política. Ele é o que nos faz pensar o outro com solidariedade, saber que o outro é uma extensão daquilo que pensamos de nós mesmos.

Devemos refletir se o mínimo existencial é obrigação do Estado. Quando alguém pede uma liminar no Supremo Tribunal Federal para garantir a realização 
de alguma operação cirúrgica de alto risco pelo SUS com algum medicamento especial, a tendência do juiz é deferir o pedido, ainda mais se a pessoa corre risco de morte. Sabemos da existência de abusos e fraudes, mas também sabemos que a pessoa pode morrer em virtude de alguma negligência por parte de quem deveria oferecer assistência.

O constitucionalismo contemporâneo assevera que o princípio da dignidade da pessoa humana somente é cumprido quando há outro princípio constitucionalmente estabelecido, o da solidariedade.

Importante que o cidadão conheça os seus direitos e saiba do acesso à justiça. Do contrário, nada terá valor. O papel do Poder Judiciário, considerando-se que o princípio está na norma e a norma é para ser cumprida, é garantir seu cumprimento integral. Portanto, o Estado deve cumprir sua obrigação, ou seja, garantir o direito do cidadão à educação, à saúde, ao trabalho, à moradia, ao lazer, à previdência, à maternidade, à infância, ao amparo aos necessitados, à assistência. São nove núcleos apenas no art. $6^{\circ}$ da Carta Magna.

Para que o direito constitucional contemporâneo seja cumprimento é necessária a participação ativa da sociedade. O direito ao trabalho e o direito à saúde já são conquistas garantidas, logo, em nome da reserva do possível, o Poder Judiciário deve deferir certos pedidos para não aniquilar direitos conquistados. E toda essa demanda precisa ser pensada como constitucionalismo social. Penso que minha principal dificuldade com o modelo econômico atualmente seja devido ao individualismo exacerbado, à intolerância, os quais são mais arraigados do que os sentimentos da minha geração. A geração atual é menos solidária.

Quando me deparo com essas dificuldades, percebo que devemos repensar como a sociedade assume o Estado, o país e, principalmente, o direito constitucional. Esse mesmo direito que garante com atuação direta, responsável e permanente a dignidade da pessoa humana e o mínimo existencial. 